This PDF is a selection from a published volume from the National Bureau of Economic Research

Volume Title: The Risks of Financial Institutions

Volume Author/Editor: Mark Carey and René M. Stulz, editors

Volume Publisher: University of Chicago Press

Volume ISBN: 0-226-09285-2

Volume URL: http://www.nber.org/books/care06-1

Conference Date: October 22-23, 2004

Publication Date: January 2007

Title: Pillar 1 versus Pillar 2 under Risk Management

Author: Loriana Pelizzon, Stephen Schaefer

URL: http://www.nber.org/chapters/c9614 


\title{
Pillar 1 versus Pillar 2 under Risk Management
}

\author{
Loriana Pelizzon and Stephen Schaefer
}

\subsection{Introduction}

Under the New Basel Accord, bank capital adequacy rules (Pillar 1) are substantially revised - but the introduction of two new dimensions to the regulatory framework is, perhaps, of even greater significance. Pillar 2 increases the number of instruments available to the regulator: (1) intensifying monitoring, (2) restricting the payment of dividends, (3) requiring the preparation and implementation of a satisfactory capital-adequacy restoration plan, and (4) requiring the bank to raise additional capital immediately. Pillar 3 enhances disclosure (that is, publicly available information). This paper investigates the consequences of adding Pillar 2 alongside Pillar 1 in terms of bank risk taking and the scale of bank lending. The results suggest that Pillar 2 should more properly be seen as a substitute for, rather than a complement to, Pillar 1, and that, in particular, Pillar 2 affects bank risk taking only when Pillar 1 rules cannot be effectively enforced.

If regulators are able to enforce a risk-based capital requirements rule at all times, then both failure and, consequently, calls on the deposit insurance fund can be effectively eliminated. In this case, the details of the rule are of little importance because as soon as capital reaches some lower threshold ${ }^{1}$ the regulator simply has to force the bank to invest entirely in

We gratefully acknowledge conversations with Mark Carey, Mark Flannery, Patricia Jackson, Ed Krane, Daniel Nuxoll, James O'Brien, Jack Reidhill, Marc Saidenberg, René Stulz, and seminar audiences at National Bureau of Economic Research (NBER) workshops in Boston, 2004, and Woodstock, 2004. All errors are our own. Financial support by NBER is gratefully acknowledged.

1. The conclusion that continuous monitoring and perfect liquidity would eliminate the possibility of default rests on the assumption of asset price continuity, that is, the absence of jumps. In the context of a single obligor this assumption is indeed critical but, for banks with 
riskless assets. Under these conditions additional regulatory instruments such as Pillars 2 and 3 would have no role. ${ }^{2}$ Thus, the design of capital requirements is a significant problem only in the case when the regulator is either unable to observe the bank's portfolio perfectly or lacks the authority to force changes in its composition. In this event, and if they are able to change their portfolio composition over time - that is, engage in risk management ${ }^{3}$ - banks may deliberately deviate from compliance with capital adequacy rules, in other words, they may cheat. Under these circumstances, instruments such as Pillar 2 and Pillar 3 may not be redundant. Our paper focuses on the interaction between Pillar 1 and Pillar 2 when banks are able to use risk management to cheat in relation to capital requirements.

We construct a model of bank behavior in which banks manage their portfolios in the interests of their shareholders subject to the constraints imposed by regulation. These regulatory constraints include not only capital requirements but actions on closure and recapitalization taken by the regulator under the new Pillar 2.

Our model has three main innovations. First, the model includes both costly recapitalization and dynamic portfolio management. The latter means that banks are concerned about survival as well as exploiting deposit insurance. Second, we consider explicitly a regime in which banks' compliance with capital requirements is imperfect; that is, a world where banks can cheat. In our analysis we consider two cases. In the first, the implementation of capital requirements is relatively effective and banks are constrained to be quite close to compliance at all points in time. In the second, the implementation of capital requirements is less effective, allowing banks to deviate substantially from the ideal of compliance at all points in time. Thus, in the first of these cases there is extensive cheating and, in the second, only limited cheating. Third, we model Pillar 2 as a threshold level such that, if a bank's capital falls below this level at the time of an audit, it must either recapitalize or face closure. This view of Pillar 2 is similar to the concept of Prompt Corrective Action (PCA) promulgated by the FDIC. This additional constraint on the bank's capital position gives the regulator an extra degree of freedom. In this sense it is therefore a simple

large, well-diversified portfolios, the conclusion is much more robust-in the sense that a jump in the value of a claim on a single counterpart would have only a small effect on the value of the portfolio as a whole.

2. A similar point is made by Berlin, Saunders, and Udell (1991, p. 740), who point out that, with perfect observability, even capital requirements are redundant and could be replaced by a simple closure rule: "A credible net-worth closure rule for banks relegates depositor discipline to a minor role. Indeed, a totally credible and error- and forbearance free closure rule removes any need for depositors to monitor bank risk at all since they would never lose on closure."

3. We use the term risk management to include any action that (deliberately) changes the risk of the bank's position over time. 
constraint on leverage. We also consider the case when a bank that recapitalizes at the Pillar 2 threshold level incurs a fixed cost. This cost may be thought of as an increase in compliance costs brought about by more intensive scrutiny on the part of the regulator, the frictional cost of recapitalization or, simply, as a fine.

Our analysis addresses the trade-off between the costs and benefits of the regulatory framework. Thus we need to consider not only measures of the negative externalities associated with bank failure but also some measure of the cost of regulation imposed by constraining bank activity. Therefore we include the probability of bank closure and the value of deposit insurance liabilities (PVDIL) as measures of the negative externalities of bank risk taking, and the average investment in risky assets and capital utilization as, respectively, measures of bank activity, to reflect the negative externality of reduced activity induced by regulation, and the private costs associated with high capital levels.

Our paper focuses on two main questions: (1) what is the effect of riskbased capital regulation (RBCR) on the trade-off between the costs and benefits of banking activity (a) when the bank manages its portfolio dynamically; (b) when, at the time of an audit, the bank's capital is below a certain threshold level, the bank must either recapitalize or it will be closed and (c) when banks' compliance with RBCR is imperfect? and (2) how does the answer to the first question change when the regulator imposes a Pillar 2/PCA leverage constraint in addition to RBCR?

In our results we distinguish between a regime where there is only limited cheating and where there is extensive cheating. In the first case, RBCR are still effective in that they reduce the cost of failure as measured by the probability of closure and the PVDIL. Importantly, when there is limited cheating, we find that the level of investment in risky assets is relatively unaffected by the level of RBCR. On the other hand, when there is extensive cheating, we find that increasing capital requirements reduces banks' investment in risky assets and increases the probability of failure.

In relation to question (2), we ask whether an intervention rule in the spirit of Pillar 2/PCA and based simply on leverage rather than portfolio risk is effective in conjunction with RBCR. We show that Pillar 2/PCA is indeed effective in reducing PVDIL: substantially when there is extensive cheating, and more modestly when there is limited cheating. When there is only limited cheating, Pillar 2/PCA increases the probability of bank closure and decreases the amount invested in risky assets. In the latter case, and especially taking into account the costs of more frequent recapitalization, it is possible that the net benefits of Pillar 2/PCA may be negative.

The paper is organized as follows. Sections 8.2 and 8.3 describe the New Basel Accord and its main advantages and drawbacks. Section 8.4 describes the model and characterizes the bank's optimal investment decisions. Section 8.5 introduces the costs of recapitalization and examines 
their effect on dynamic portfolio management. Section 8.6 extends the analysis introducing risk-based capital requirements (Pillar 1). Section 8.7 presents the results of the interaction between Pillar 1 and Pillar 2, and section 8.8 concludes.

\subsection{The New Basel Accord: A Brief Description}

In the early 1980s, as concern about the financial health of international banks mounted and complaints of unfair competition increased, the Basel Committee on Banking Supervision initiated a discussion on the revision of capital standards. An agreement was reached in July 1988, under which new rules would be phased in by January 1993 (Basel Committee 1988). The Basel Accord of 1988 explicitly considered only credit risk, and the scheme was based entirely on capital requirements. These requirements, still in force, comprise four elements: (1) the definition of regulatory capital, (2) the definition of the assets subject to risk weighting, (3) the risk weighting system, and (4) the minimum ratio of 8 percent. ${ }^{4}$

When the Accord was introduced in 1988, its design was criticized as being too crude and for its one-size-fits-all approach. ${ }^{5}$ Given these shortcomings, together with the experience accumulated since the Accord was introduced, the Basel Committee is considering revising the current accord (Basel Committee 1999, 2001, 2003, 2005).

The proposed new accord differs from the old one in two major respects. First, it allows the use of internal models by banks to assess the riskiness of their portfolios and to determine their required capital cushion. This applies to credit risk as well as to operational risk, and delegates to a significant extent the determination of regulatory capital-adequacy requirements. This regime is available to banks if they choose this option and if

4. Following its introduction, the accord has been fine-tuned to accommodate financial innovation and some of the risks not initially considered. For example, it was amended in 1995 and 1996 to require banks to set aside capital in order to cover the risk of losses arising from movements in market prices. In 1995, the required capital charge was based on the "standard approach" similar to that applied to credit risk. The standard approach defines the risk charges associated with each position and specifies how any risk position has to be aggregated into the overall market risk capital charge. The amendment of 1996 allows banks to use, as an alternative to the standard approach, their internal models to determine the required capital charge for market risk. The internal model approach allows a bank to use its model to estimate the Value-at-Risk (VaR) in its trading account; that is, the maximum loss that the portfolio is likely to experience over a given holding period with a certain probability. The market risk capital requirement is then set based on the VaR estimate. The main novelty of this approach is that it accounts for risk reduction in the portfolio resulting from hedging and diversification.

5. The main criticisms were, among other things, (1) the capital ratio appeared to lack economic foundation, (2) the risk weights did not reflect accurately the risk of the obligor, and (3) it did not account for the benefits from diversification. One of the main problems with the existing accord is the ability of banks to arbitrage their regulatory capital requirements (see Jones 2000) and exploit divergences between true economic risk and risk measured under the accord. 
their internal model is validated by the regulatory authority. Second, by adding two additional pillars alongside the traditional focus on minimum bank capital, the new accord acknowledges the importance of complementary mechanisms to safeguard against bank failure. Thus, the new capital adequacy scheme is based on three pillars: (1) capital adequacy requirements (Pillar 1), (2) supervisory review (Pillar 2), and (3) market discipline (Pillar 3).

With regard to the first pillar, the Committee proposes two approaches. The first, so-called "standardized" approach, adopts external ratings, such as those provided by rating agencies, export credit agencies, and other qualified institutions. The second approach, called the "Internal ratingbased approach," allows the use of internal rating systems developed by banks (subject to their meeting specific criteria yet to be defined), and validation by the relevant national supervisory authority. The internal ratings approach is also divided in two broad approaches: the "advanced" and the "foundation." The former gives some discretion to banks in choosing the parameters that determine risk weights, and consequently, in determining their capital requirements. The foundation approach, in contrast, provides little discretion. ${ }^{6}$

As far as the second pillar is concerned, the proposals of the Basel Committee underline the importance of supervisory activity such as reports and inspections. These are carried out by individual national authorities who are authorized to impose, through moral suasion, higher capital requirements than the minimum under the capital adequacy rules. In particular, Pillar 2 emphasizes the importance of the supervisory review process as an essential element of the new Accord (see Santos 2001). Pillar 2 encourages banks to develop internal economic capital assessments, appropriate to their own risk profiles, for identifying, measuring, and controlling risks. The emphasis on internal assessments of capital adequacy recognizes that any rules-based approach will inevitably lag behind the changing risk profiles of complex banking organizations. Banks' internal assessments should give explicit recognition to the quality of the risk management and control processes and to risks not fully addressed in Pillar 1. Importantly, Pillar 2 provides the basis for supervisory intervention and allows regulators to consider a range of options if they become concerned that banks are not meeting the requirements. These actions may include more intense monitoring of the bank; restricting the payment of dividends; requiring the bank to prepare and implement a satisfactory capital-adequacy restoration plan; and requiring the bank to raise additional capital immediately. Supervisors should have the discretion to use the tools best suited to the

6. In addition to revising the criteria for the determination of the minimum capital associated to the credit risk of individual exposures, the reform proposals advanced by the committee introduce a capital requirement for operational risks, which is in turn determined using three different approaches presenting a growing degree of sophistication. 
circumstances of the bank and its operating environment (New Accord: Principle 4: 717).

Finally, the third pillar is intended to encourage banks to disclose information in order to enhance the role of the market in monitoring banks. To that end, the Committee is proposing that banks disclose information on, among other things, the composition of their regulatory capital, risk exposures, and risk-based capital ratios computed in accordance with the Accord's methodology.

In the light of these objectives, the Basel Committee has articulated four principles: (1) Each bank should assess its internal capital adequacy in light of its risk profile, (2) Supervisors should review internal assessments, (3) Banks should hold capital above regulatory minimums, and (4) Supervisors should intervene at an early stage.

The descriptions of the second and third pillars by the Basel Committee are not as extensive or detailed as that of the first. Nevertheless, it is significant that for the first time in international capital regulation, supervision and market discipline are placed at the same point of the hierarchy as the regulatory minimum. In discussing the second pillar the proposal states that: "The supervisory review process should not be viewed as a discretionary pillar but, rather, as a critical complement to both the minimum regulatory capital requirement and market discipline" (Basel Committee 1999, p. 53).

In this paper we analyze the effects of Pillar 2 intervention and, in particular, the interaction between Pillar 2 and Pillar 1. We characterize Pillar 2 as a threshold level of leverage such that a bank with higher leverage than this threshold at the time of an audit is required either to recapitalize or to close. If a bank recapitalizes it incurs a cost. This characterization is therefore firmly in the spirit of both PCA and Basel II.

We show first that Pillar 2 intervention has a significant impact on the frequency of bank closure and the value of deposit insurance liabilities only when regulators are unable to force banks to comply with Pillar 1 riskbased capital requirements at all times. This may arise, for example, as the result of monitoring costs. If banks always comply with risk-based capital requirements then both failure rates and the present value of deposit insurance liability go to zero. ${ }^{7}$

However, if banks do not always comply with Pillar 1 capital requirements, Pillar 2 may have a role, by inducing banks to manage their portfolios so as to reduce the likelihood of incurring recapitalization costs. A central issue that we explore in the paper is the interaction between the level of risk-based capital requirements (Pillar 1), the threshold leverage level (Pillar 2) and the degree of noncompliance with Pillar 1 rules. More particularly, we investigate whether, as the regulators hope, Pillar 2 does indeed act

7. Unless there are jumps in the value of the portfolio of bank assets. 
as complement to Pillar 1 -in the sense that it increases the effectiveness of Pillar $1-$ or whether it is simply a substitute, a second line of defense.

\subsection{Advantages and Main Drawbacks of the New Accord}

The Basel Committee's proposals can be seen as an attempt to address some of the drawbacks of the previous capital adequacy scheme. In particular, the new accord represents an advance in three main areas. First, with the objective of making capital requirements more risk sensitive, it introduces a more accurate framework for the assessment of risk, in particular credit risk. Although the new proposals have undoubtedly raised the level of the analysis of credit risk from the first accord, there remain some important questions about some aspects; for example, how the correlation of credit exposures is treated. Moreover, for the first time the rules explicitly include operational risk as one of the determinants of required capital (Pillar 1). The new rules will also enhance the role of banks' internal assessments of risk as the basis for capital requirements. Second, the new accord represents an attempt on the part of regulators to lower the impact of capital regulation as a source of competitive inequality by reducing the opportunity for regulatory arbitrage. Third, the new accord enhances the role for regulatory review and intervention (Pillar 2) and market discipline (Pillar 3).

In introducing an extension to the current accord that concentrates only on capital requirements, Basel II is more consistent with the consensus of the literature on asymmetries of information; that, in general, it is advantageous to consider a menu-based approach rather than a uniform onesize-fits-all rule. ${ }^{8}$ The limitations of a simple capital-adequacy approach in our paper arise when bank portfolios are imperfectly observable by the auditor and banks are able to engage in dynamic portfolio management.

Nonetheless, it appears that the new accord does have some significant weaknesses and, among these, we draw particular attention to the following.

A major problem - long present in the literature - in assessing developments in banking regulation, and financial regulation in general, is that there is little discussion, and certainly no consensus, on the objectives that the regulator should pursue (Dewatripont and Tirole 1994). The two mostcommonly cited justifications for bank regulation, and capital regulation in particular, are (1) the mitigation of systemic risks (see Goodhart et al. 1998, and Benston and Kaufman 1996 among others) and (2) the need to control the value of deposit insurance liabilities (see Merton 1997, Genotte

8. See Kane (1990) and Goodhart et al. (1998) for a discussion of the principal-agent problems that can arise between regulators and regulated, and Hauswald and Senbet (1999) for the design of optimal banking regulation in the presence of incentive conflicts between regulators and society. For other analysis of the interplay between capital regulation and monitoring of the bank by a regulator, see Campbell, Chan, and Marino (1992) and Milne and Whalley (2001). 
and Pyle 1991, Buser, Chen, and Kane 1981, Chan, Greenbaum, and Thakor 1992, and Diamond and Dybvig 1986, among others). Indeed, the authors of the Basel II proposals refer to their "fundamental objective ... . to develop a framework that would further enhance the soundness and stability of the international banking system."

Thus it might seem curious to an outsider that the new Basel II accord is so little concerned with the problem of systemic risk, which has for so long been seen as central to the design of bank regulation. Nonetheless we find this nonsystemic same view expressed repeatedly by the regulators in describing the goals of the new accord. For example, the following quotation, which comes from the Bank for International Settlements (BIS) itself, addresses what we would regard as some of the central questions in bank regulation, and does so without any reference to systemic costs:

Why are banks subject to capital requirements?

Nearly all jurisdictions with active banking markets require banking organizations to maintain at least a minimum level of capital. Capital serves as a foundation for a bank's future growth and as a cushion against its unexpected losses. Adequately capitalized banks that are well managed are better able to withstand losses and to provide credit to consumers and businesses alike throughout the business cycle, including during downturns. Adequate levels of capital thereby help to promote public confidence in the banking system.

Why is a new capital standard necessary today?

Advances in risk management practices, technology, and banking markets have made the 1988 Accord's simple approach to measuring capital less meaningful for many banking organizations.

What is the goal for the Basel II Framework and how will it be accomplished?

The overarching goal for the Basel II Framework is to promote the adequate capitalization of banks and to encourage improvements in risk management, thereby strengthening the stability of the financial system. This goal will be accomplished through the introduction of "three pillars" that reinforce each other and that create incentives for banks to enhance the quality of their control processes. (BIS 2004)

The connection between the objective of enhancing the "soundness and stability" of the banking system and the specifics of the proposal, particularly in relation to systemic risk, are unclear. More broadly, the Basel II Accord is almost silent on the presence of externalities such as systemic failure and contagion, which would be regarded by many as the principal justification for regulatory intervention (Berlin, Saunders, and Uddell 1991, Allen and Gale 2003). Without externalities, decisions-for example, on capital structure - that are optimal from the private perspective of bank owners would also be socially optimal and, in this case, there would be no need for regulation. 
The "externality-free" view of regulation that Basel II appears to espouse is also reflected in Pillar 3. This seeks to "encourage market discipline by developing a set of disclosure requirements that allow market participants to assess key information about a bank's risk profile and level of capitalization" (Basel Committee 2005, p. 184). However, it is unclear what impact greater transparency would have. If capital requirements are set without reference to the social costs of failure - that is, regulatory capital requirements coincide with privately optimal levels of capital - then banks are, in any case, incentivized to maintain these levels, and greater transparency would have little effect. If capital requirements do reflect the social costs of failure - that is, are higher than those banks would choose privately - then it is not clear how disclosing to a private counterparty a deficit against regulatory capital requirements would give the bank any incentive to increase capital.

When systemic costs are taken into account, optimal regulatory design involves trading off the social benefits of, for example, a lower frequency of failure with the private costs of achieving this. But when systemic issues are excluded from the analysis, there is no trade-off, because the interests of private owners and social welfare coincide. In this case the prescriptions of the regulator are those that the bank would optimally choose for itself and the regulator becomes a sort of "super consultant" helping to promote good practice and sound analysis. These are worthy objectives, but it is unclear why they need to be promoted within a legal framework such as Basel II. For example, the Basel Committee states that it "believes that the revised framework will promote the adoption of stronger risk management practices by the banking industry" (Basel Committee 2005, p. 2). While undoubtedly desirable, it is not clear how improving management practice in the area of risk management addresses the broad objectives of soundness and stability or, indeed, that banks themselves are not in a better position to decide on the appropriate level of investment in risk management.

The absence in the Basel Accord of any substantial discussion of costs is a major omission. ${ }^{9}$ For example, if the costs imposed by capital requirements were small while the social costs of failure were significant, required capital should be set to sufficiently high levels that the incidence of bank failure would be minimal. The fact that no bank regulator proposes such a regime suggests that regulators at least consider that the costs imposed by capital regulation are significant. Certainly the U.S. House of Representa-

9. References to the cost of capital requirements by the Basel Committee are rare. Among the small number of examples, the following quotation makes an implicit reference to cost when it refers to the possibility that capital level might be "too high": "The technical challenge for both banks and supervisors has been to determine how much capital is necessary to serve as a sufficient buffer against unexpected losses. If capital levels are too low, banks may be unable to absorb high levels of losses. Excessively low levels of capital increase the risk of bank failures which, in turn, may put depositors' funds at risk. If capital levels are too high, banks may not be able to make the most efficient use of their resources, which may constrain their ability to make credit available" (BIS, 2004, p. 1). 
tives Committee on Financial Services (USHRCFS) has reservations about the costs imposed by capital requirements: "We are concerned that the bank capital charges created by Basel II, if implemented, could be overly onerous and may discourage banks from engaging in activities which promote economic developments." 10

In our analysis we reflect the trade-off between, on one hand, the public and private costs of failure and, on the other, the costs imposed by regulation. Ideally, alternative designs for Basel II would find the best trade-off between these costs using a general equilibrium approach. ${ }^{11}$ In the absence of such a model, we focus on four outcome variables that are plausible candidates for the arguments of the welfare function that might be derived from an equilibrium model.

The first is the PVDIL: the cost of insuring deposits. The second is the frequency of bank closure, which we regard as an index of the systemic cost of failure. All else equal, a low frequency of failure would promote confidence in the banking system and enhance the efficiency of the payments mechanism (see Diamond and Dybvig 1986).

Third, there is a widely held - if imperfectly articulated - view, reflected in the concerns expressed by the USHRCFS, that high levels of capital impose a cost on banks. In our analysis we use the average level of bank capital as a measure of this cost.

Finally, we wish to capture the positive externalities that may arise from banking activity, for example, bank lending. Clearly, a capital requirements regime that was so onerous as to substantially eliminate banking activity would also reduce both the frequency of failure and the PVDIL to zero. A former chairman of the London Stock Exchange once referred to this approach as the "regulation of the graveyard." The previous quotation from the USHRCFS suggests that they share these concerns and so we also report the average level of risky assets held as a proxy for banks' contribution to economic activity through lending.

The Basel Committee has attempted to assess the potential impact of the new accord on capital requirements for different types of banks in a variety of countries by carrying out Quantitative Impact Studies (QIS). These entail each bank recalculating capital requirements for its current portfolio under the new accord. However, the QIS calculations were conducted under ceteris paribus assumptions and did not attempt to take into account any behavioral response on the part of banks to the new accord. One of the aims of this paper is to provide a framework within which the behavioral response of banks to changes in regulation might be studied.

10. U.S. House of Representatives Committee on Financial Services letter to the chairmen of the Federal Reserve and the FDIC, the Comptroller of the Currency and the Director of the Office of Thrift Supervision, November 3, 2003, p. 2.

11. See, for example, Suarez and Repullo (2004). However, defining an appropriate social welfare function is always problematical. 
Pillars 2 and 3 are major innovations in the new accord and represent an explicit recognition that capital supervision involves more than capital requirements. Pillar 2, in particular, adds an important instrument to the bank regulator's armory and allows for some discretion over important elements such as closure, dividend payments, and recapitalization. Pillar 3 , by encouraging transparency, attempts to capture the benefits of market discipline. However, two important issues remain. First, as other authors (see Saidenberg and Schuermann 2003 and von Thadden 2003) have pointed out, there is a substantial imbalance in the detail provided by the committee between Pillar 1, on one hand, and Pillars 2 and 3 on the other. The focus of the committee's attention seems clear. Second, and more important, there is no discussion of the interaction between capital rules and market discipline and the rules governing closure, dividend payments, and recapitalization.

The main aim of this paper is to try to provide a framework within which to analyze the relations between capital requirements and closure, dividend payments, and recapitalization. Descamps, Rochet, and Roger (2003) have also drawn attention to the importance of this issue.

Finally, one aspect of the objectives of Basel II is to ensure that "capital adequacy regulation will not be a significant source of competitive inequality among internationally active banks" (Basel Committee 2005, p. 2). However, trying to make regulation neutral with respect to competition (the level playing field) is a more demanding objective. First, regulation almost inevitably affects competition because it affects bank costs. Second, if the regulator attempts to design capital requirements, say, by finding the optimal trade-off between private and social costs, then capital rules will almost inevitably vary across banks unless they are all identical in terms of their social costs (e.g., of failure). Differentiation of this kind-for example, between large banks and small banks - is not found in the Basel II rules or, indeed, in other capital adequacy regimes. It appears that the pressure on regulators for equal treatment among banks dominates a more fine-tuned approach to regulatory design.

\subsection{The Model}

\subsubsection{Timing and Assumptions}

In our model a bank is an institution that holds financial assets and is financed by equity and deposits.

\section{Bank Shareholders and Depositors}

Shareholders are risk neutral, enjoy limited liability, and are initially granted a banking charter. The charter permits the bank to continue in business indefinitely under the control of its shareholders unless, at the 
time of an audit, the regulator finds the bank is in violation of regulations such as capital requirements. In this case the charter is not renewed, the shareholders lose control of the bank, and the value of their equity is zero.

If the bank is solvent at time $t-1$, it raises deposits ${ }^{12} D_{t-1}$ and capital $k D_{t-1}, k>0$ so that total assets invested are

$$
A_{t-1}=(1+k) D_{t-1} .
$$

The deposits are one-period term deposits paying a total rate of return of $r^{d}$. Thus, at maturity the amount due to depositors is

$$
D_{t}=D_{t-1}\left(1+r^{d}\right) \text {. }
$$

At this point, if the bank is solvent, the accrued interest, $r^{d} D_{t-1}$, is paid to depositors and deposits are rolled over at the same interest rate.

\section{Regulators and Audit Frequency}

We assume that audits take place at fixed times $t=1,2, \ldots$ The government guarantees the deposits and charges the bank a fixed premium per dollar of insured deposits that is the same for all banks. ${ }^{13}$ This premium is included in the deposit rate $r^{d} \cdot{ }^{14}$

\section{Portfolio Revisions and Investment Choice}

Between successive audit dates there are $n$ equally spaced times at which the portfolio may be revised. Setting $\Delta t \equiv 1 / n$, the portfolio revision dates, between audit dates $t$ and $t+1$, are therefore

$$
t, t+\Delta t, t+2 \Delta t, \ldots \ldots, t+(n-1) \Delta t, t+1 .
$$

For simplicity we assume that the bank may choose between two assets: a risk-free bond with maturity $1 / n$, yielding a constant net return $\hat{r}$ per period of length $1 / n$ ( $r$ per period of length 1$)$ and a risky asset yielding a gross random return $R_{t+j \Delta t}$ over the period $(t+[j-1] \Delta t)$ to $(t+j \Delta t) .{ }^{15}$ Returns on the risky asset are independently distributed over time and have a constant expected gross return of $E\left(R_{t+j \Delta t}\right) \equiv(1+\hat{a})$, where $\hat{a}$ is the net expected return per period of length $1 / n$ ( $a$ per period of length 1$)$. Notice that we assume that, at each portfolio revision date, the bank is allowed either to increase or decrease its investment in the risky asset; that is, the risky asset is marketable.

In our model we assume that the only source of bank rent is deposit insurance - that is, $r^{d}=r=a$. This may appear to be a very pessimistic view

12. We take the volume of a bank's deposits as exogenous.

13. This means that the deposit insurance premium is not risk dependent and is therefore not actuarially fair.

14. Equivalently, we may interpret this arrangement as one where the depositors pay the deposit insurance premium and receive a net interest rate of $r^{d}$.

15. This means that we do not address the issues related to portfolio diversification as in Boot and Thakor (1991). 
of banking, as in this case a bank's only objective is to try to exploit deposit insurance. However, we know that when banks have other sources of rents this acts as a natural curb on excessive risk taking and capital requirements will be less necessary. In our framework the banks that are most likely to default are those without other significant sources of rents, who will try to hold as little capital as possible.

In making these assumptions we have in mind a competitive market where the surplus associated with the projects financed by loans is captured entirely by the borrowers. The presence of a borrower surplus means, as we have mentioned earlier, that lending is, on average, improving welfare. For this reason, again as mentioned earlier, we use the volume of risky assets held by the bank as one argument of a measure of welfare.

\section{Portfolio Choice}

Let $w_{t+j \Delta t}$ denote the percentage of the portfolio held in the risky asset at time $t+j \Delta t$, with the remainder invested in the "safe" security. We limit the leverage that the bank can take on by imposing a no-short selling constraint $\left(0 \leq w_{t+j \Delta t} \leq 1\right)$ on both the risky and safe assets: ${ }^{16}$

$$
0 \leq w_{t+j \Delta t} \leq 1 \forall t \in(0, \infty), \forall j \in(0, n-1)
$$

The bank's portfolio management strategy is represented as a sequence of variables $\Theta=\left(\theta_{0}, \theta_{1}, \ldots, \theta_{t}, \ldots, \theta_{\infty}\right)$, with

$$
\theta_{t}=\left(w_{t}, w_{t+\Delta t}, \ldots, w_{t+j \Delta t}, \ldots, w_{t+j \Delta t}, \ldots, w_{t+(n-1) \Delta t}\right) \text { for all } 0 \leq t \leq \infty .
$$

and $0 \leq j \leq n-1$, where $\theta_{t}$ represents the strategy between audit dates $t$ and $t+1$ and $\Theta$ the collection of these substrategies for audit dates $1,2, \ldots$, $t, \ldots \infty$.

\section{Intertemporal Budget Constraint}

The intertemporal budget constraint is given by

$$
A_{t+(j+1) \Delta t}=\left[w_{t+j \Delta t} R_{t+j \Delta t}+\left(1-w_{t+j \Delta t}\right)(1+\hat{r})\right] A_{t+j \Delta t},
$$

and so the bank's asset value at the audit time $t+1$ is

$$
A_{t+1}=\prod_{j=0}^{n-1}\left[w_{t+j \Delta t} R_{t+j \Delta t}+\left(1-w_{t+j \Delta t}\right)(1+\hat{r})\right] A_{t} .
$$

\section{Bank Closure Rule (Transfer of Control from Shareholders to Supervisor)}

Most of the previous literature has assumed a closure rule under which banking authorities deny the renewal of the banking license and close the

16. It may not be immediately apparent that a nonnegativity constraint on the risky asset would ever be binding. However, under the assumptions that we introduce (limited liability) we show that the bank will be risk preferring in some regions and would short the risky asset if it could. 
bank if its net worth (asset value minus deposits) is negative at the end of a period - that is, if the asset value is lower than the threshold point represented by the deposit value (Marcus 1984, Keeley 1990, Hellman, Murdock, and Stiglitz 2000, and Pelizzon and Schaefer 2003). This closure rule induces the bank to be prudent when the bank has a sufficiently high rent from deposit insurance, interest ceilings, or monopoly power in the deposit or asset market. Such a closure policy serves as a mechanism that both manages bank distress ex post and may also have a disciplinary effect on ex ante actions. A major drawback of this approach, however, is that shareholders who wish to provide capital to reestablish solvency are prevented from doing so. Among the problems raised by this assumption is the question of whether, by refusing to allow recapitalization, the government would be illegally expropriating the property of bank shareholders.

Thus, in this paper we consider the case where the banking authorities, instead of closing the bank or intervening and assuming control (for equityholders this is the same as closing the bank), allow recapitalization by shareholders ${ }^{17}$ and renewal of the license if, after recapitalization, the volume of capital meets a given minimum threshold level, $\bar{k} \cdot{ }^{18}$ In the papers cited in the previous paragraph, $\bar{k}$ is a small quantity of capital that guarantees solvency. Later in the paper, where we introduce Pillar 2/PCA, this threshold will be higher.

Under this rule, equityholders have an option to retain the banking license. They will exercise this option when there is an amount of capital, $k^{*}$ $\geq \bar{k}$, such that the volume of capital the bank shareholders need to raise, $k^{*} D+D_{t}-A_{t}$, is lower than the value of equity, $S$, after recapitalization.

More formally, let the indicator variable $I_{t}$ represent whether the bank is open $\left(I_{t}=1\right)$ or closed $\left(I_{t}=0\right)$ at time $t$,

$$
I_{t}=\left\{\begin{array}{l}
0 \text { if } \prod_{s=0}^{t-1} I_{s}=0 \\
0 \text { if } \prod_{s=0}^{t-1} I_{s}=1 \text { and } S<k^{*} D+D_{t}-A_{t}, \\
1 \text { if } \prod_{s=0}^{t-1} I_{s}=1 \text { and } S>k^{*} D+D_{t}-A_{t}
\end{array}\right.
$$

with $I_{0}=1$.

17. Other authors consider this option. See Suarez (1994), Fries, Barral, and Perraudin (1997), and Pages and Santos (2003), among others.

18. A typical situation is when bank losses are covered by bank mergers and acquisitions. In our framework, it is the same if capital is replenished by old or new shareholders; the key point is that old shareholders do not lose 100 percent of the franchise value. Dewatripont and Tirole (1994) state that this closure policy is very common in the United States (73.8 percent).

Another rescue policy documented by Dewatripont and Tirole (1994) is the "open bank assistance" policy, also called "bail-out." In a bail-out the bank liquidates the defaulted assets, the government covers the shortfall to the depositors whose claims are in default, and the bank is not closed. This rescue policy is assimilable to our closure rule if shareholders still maintain a proportional claim on the bank franchise value. It is also assimilable to the government takeover when the bank is completely nationalized. 


\section{Dividend Policy and Capital Replenishment}

With this new feature, the shareholder cash flow (a dividend, if positive, or equity issue amount, if negative) is

$$
d_{t}=\left\{\begin{array}{l}
A_{t}-D_{t}-k^{*} D \text { if } S \geq D_{t}+k^{*} D-A_{t} \\
0 \text { otherwise. }
\end{array}\right.
$$

\subsubsection{The Problem}

The bank chooses its investment policy $\theta_{t}^{*}$, (i.e., the percentage $w_{t+j \Delta t}^{*}$ invested in the risky asset at each time $t+j \Delta t$ ) and the level of capital after recapitalization, $k^{*}$. The value of equity is given by the present value of future dividends:

$$
S_{0}=\sum_{t=1}^{\infty}(1+r)^{-t} E\left[d_{t}\left(\theta_{t}, k_{t}\right)\right]
$$

The problem faced by the bank is to choose the policy $\left(\theta_{t}^{*}, k_{t}^{*}\right)$ that maximizes the value to shareholders, subject to equation (4), $k_{t}>k$, and where dividends, $d_{t}$, are defined in equation (9).

This problem is time invariant for any audit time because, if the bank is solvent at audit time $t$, then, since the distribution of future dividends at $t+1$ is identical for all $t$, the portfolio problem faced by the bank is also identical at each audit time when the bank is solvent. This means that the value of equity at time $t$, conditional on solvency, is given by ${ }^{19}$

$$
S_{t}=\left\{\begin{array}{l}
\sum_{t+1}^{\infty}(1+r)^{-(s-t)} E\left(d_{s}\right)=(1+r)\left[E\left(d_{t+1}\right)+S_{t+1}\right] \text { if } I_{t+1}=1 \\
0 \text { of } I_{t+1}=0
\end{array}\right.
$$

This quantity is constant at each audit time when the bank is solvent and can be written $\mathrm{as}^{20}$

$$
S\left(\theta^{*}, k^{*}\right)=\frac{E\left[d\left(\theta^{*}, k^{*}\right)\right]}{r+\pi\left(\theta^{*}, k^{*}\right)},
$$

where $\pi\left(\theta^{*}, k^{*}\right)$ is the probability of default at the next audit. Thus, the value of equity is equal to the expected dividend divided by the sum of riskfree rate and the probability of default. In other words, the value of equity has a character of perpetuity where the discount rate is adjusted for default. ${ }^{21}$

19. Note that $d_{t+1}$ and $S_{t+1}$ are functions of the portfolio strategy, $\theta_{t}$, and the level of capital, $k_{t}$, but, for sake of notational clarity, we suppress this dependence.

20. For details see Pelizzon and Schaefer (2003).

21. A similar relation obtained in a number of models of defaultable bonds (see Lando 1997 and Duffie and Singleton 1999). 
The bank's portfolio and capital problem may also be defined as the maximization of the franchise value, defined as the difference between the value of equity and the amount of capital, $k^{*}$, provided by shareholders:

$$
F=S\left(\theta^{*}, k^{*}\right)-k^{*} D .
$$

\subsubsection{Welfare Function Variables}

To evaluate the performance of Pillar 1 and Pillar 2 we need some measures of the welfare outcomes to which these rules give rise. In the absence of a formal welfare function, and as described earlier, we employ the following four measures: (1) the probability of bank closure, (2) the value of deposit insurance liabilities (PVDIL) as measures of the negative externalities of bank risk taking, (3) the average investment in risky assets and the capital utilization as, respectively, measures of bank activity, to reflect the positive externalities of bank lending, and (4) the private costs associated with high capital levels.

The first measure, the probability of bank closure, $\pi$, has already been described above. Using equations (9), (11), and (12), it is straightforward to show that the PVDIL of the bank can be written as

$$
\frac{E(\text { Put })}{r+\pi\left(\theta^{*}, k^{*}\right)}=\text { PVDIL, }
$$

where "Put" represents the payoff on a one-period option held by the bank on the deposit insurance scheme - that is,

$$
E_{t-1}(\mathrm{Put})=\int_{0}^{D_{t}-F}\left(D_{t}-A_{t}\right) f\left(A_{t}\right) d A_{t} \equiv E(\mathrm{Put}) .
$$

The average investment in the risky asset, $\overline{A w}$, is defined as

$$
\overline{A w}=E_{\{\omega\}}\left[\frac{1}{n-1} \sum_{j=0}^{n-1} w_{t+j \Delta t}^{*}(\omega) A_{t+j \Delta t}(\omega)\right],
$$

where the expectation of the term in square brackets is taken over paths for the asset value, $A_{t+j \Delta t}$, and portfolio proportion, $w_{t+j \Delta t}^{*}$, and where $\omega$ denotes the path.

Finally, the capital utilization is the optimal amount of capital that shareholders decide to provide at time zero and at each audit date - that is, $k^{*}$.

\subsubsection{Bank's Optimal Policy}

In this section we show that the disciplinary effect of the franchise value vanishes when closure rules allow costless recapitalization. The feedback effect of alternative closure policies on the incentives of bank owners to 
avoid financial distress warrants closer attention, a point emphasized by the wide range of such policies that regulators actually employ. ${ }^{22}$ This result is summarized in the following lemma.

LEMma 1: When recapitalization is allowed (and $F<D$ ), the optimal policy for the bank is the riskiest policy, irrespective of the source of the franchise value.

Proof.

Assuming that the risky asset distribution is lognormal and constant portfolio proportion imply that

$$
S=(1+r)^{-1} \int_{D_{t}+k D-S}^{\infty}\left(A_{t}-D_{t}-k D-S\right) f\left(A_{t}\right) d A_{t} .
$$

Clearly this is the value of a call option; increasing the investment in the risky asset the bank rises the volatility of the asset $A_{t}$ and so the value of equity (i.e., the value of the call option).

Q.E.D.

This result (already proved by Suarez 1994 for the case with deposit rents only and Pelizzon 2001 for different sources of rents) is driven by the form of the payoffs associated with one-period decisions. Under the simple rule described earlier, when closure takes place when the asset value is lower than the threshold point represented by the deposit value, the payoff to shareholders at the time of an audit, when the bank continues, is given by the sum of the dividend cash flow, $d$ (which is negative in the case of recapitalization) and the value of the equity in continuation, $S$. If, at the time of an audit, the bank is closed when $A_{t}<D_{t}$ the payoff to equityholders is zero. This is illustrated in figure 8.1.

In contrast, when recapitalization is allowed, even when the value of assets is below that of liabilities, shareholders' total payoff is given by the sum of value of equity $S$ and the dividend cash flow $d$ when the value of equity after recapitalization is higher than the amount of capital contributed $\left(S>A_{t}-D_{t}+k^{*} D\right)$, and zero otherwise. Figure 8.2 shows the total payoff in this case.

Figures 8.1 with 8.2 differ for asset values between $D_{t}+k^{*} D-S$ and $D_{t}$. The nonconvexity of the total payoff as a function of the asset value in the first case explains shareholders' aversion to risk when $F$ is sufficiently high.

22. See Dewatripont and Tirole (1994) for a comparison of rescue policies employed in the developed economies of the United States, Japan, and European Nordic countries. Legislation in general calls for increasingly strict sanctions against banks as their capital levels deteriorate (see, for example, the Prompt Corrective Action) but still permits some regulators discretion concerning the closure of banks. See also Gupta and Misra (1999) for a review of failure and failure resolution in the U.S. thrift and banking industries. 


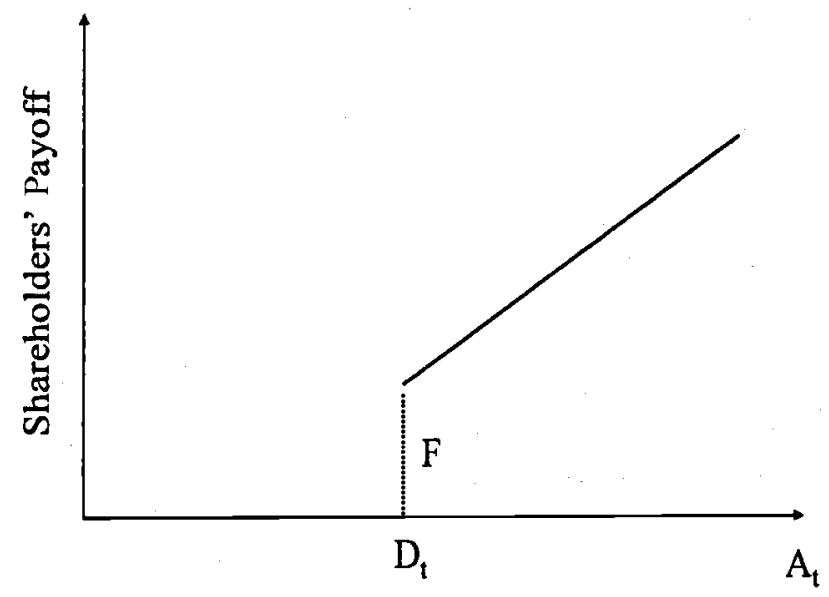

Fig. 8.1 Shareholders' payoff without the option to recapitalize

Note: This figure shows the shareholders' payoff at the next audit time under the threshold closure rule.

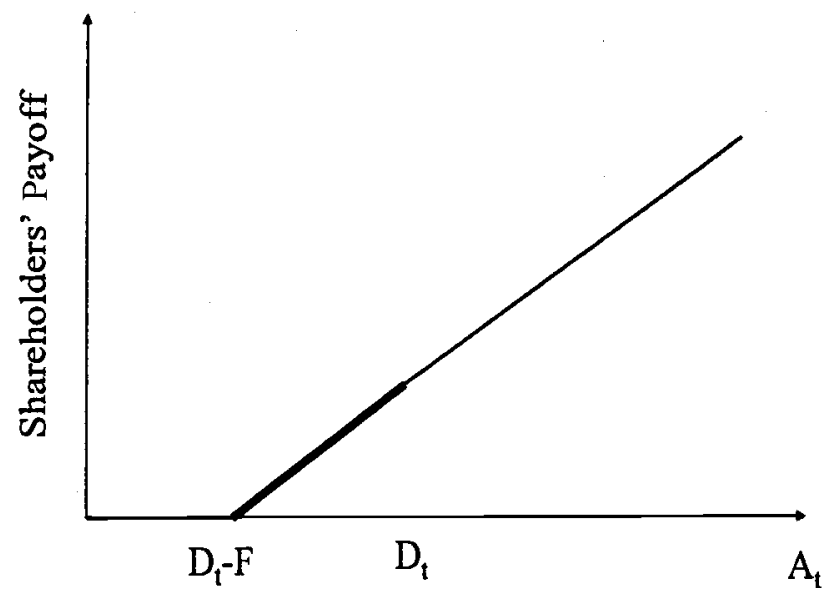

Fig. 8.2. Shareholders' payoff with the option to recapitalize

Note: This figure shows the shareholders' payoff at the next audit time under the option to recapitalize closure rule and no costs of recapitalization.

Conversely, the convexity of the total payoff in the second case induces risk loving.

As Lemma 1 states, in the case of a convex payoff function, the optimal portfolio strategy for bank is always to invest entirely in the risky asset. The option to recapitalize in this case not only induces the bank to choose the most risky strategy but also affects the probability of default and the value of deposit insurance liabilities (Pelizzon 2001). 


\subsection{Costs of Recapitalization}

Thus, the case of a convex payoff function analyzed by Suarez (1994) allows recapitalization but leads to the prediction that banks always seek to maximize risk. As a characterization of actual bank behavior this approach probably has limited descriptive power. As mentioned previously, the approach taken in earlier literature induced prudence on the part of banks, but only by expropriating the positive franchise value that insolvent banks $(A<D)$ would have had if allowed to recapitalize.

In this paper we follow Suarez (1994) in allowing recapitalization for all values of $A$, but with a frictional cost, $v$. In this case equation (9) that defines the dividend becomes

$$
d_{t}=\left\{\begin{array}{l}
A_{t}-D_{t}-k^{*} D \text { if } A_{t} \geq D_{t}+k^{*} D \\
\left(A_{t}-D_{t}-k^{*} D\right)(1+v) \text { if } S \geq D_{t}+k^{*} D-A_{t} \text { and } A_{t}<D_{t}+k^{*} D \\
0 \quad \text { otherwise. }
\end{array}\right.
$$

The presence of these costs reintroduces concavity into the bank's payoff function and, depending on the parameters, this is sufficient to induce prudence on the part of the bank. Figure 8.3 shows the payoff to shareholders as a function of the asset value where the bank incurs a variable cost of replenishing the bank's capital ${ }^{23}$ to a level $k^{*}$.

There is a second cost that banks incur when they recapitalize. This is a fixed cost, $C$, that is related to the Pillar 2/PCA intervention threshold $\hat{k}$ and, in this case, the formula defining the dividend is

$$
d_{t}=\left\{\begin{array}{l}
A_{t}-D_{t}-k^{*} D \text { if } A_{t} \geq D_{t}+k^{*} D \\
\left(A_{t}-D_{t}-k^{*} D\right)(1+v)-C \text { if } S \geq D_{t}+k^{*} D-A_{t} \\
\text { and } A_{t}<D_{t}+k^{*} D \\
0 \quad \text { otherwise. }
\end{array}\right.
$$

Our interpretation of this cost is as an increase in the direct and indirect costs of compliance that come about as a result of the regulator increasing its intensity of monitoring. This may be viewed in terms of increased direct compliance costs, diversion of management time, restrictions on new business activities, and so on. This situation is illustrated in figure 8.4 where, for simplicity, we suppress the variable cost of recapitalization that was illustrated in figure 8.3 .

23. Our model does not explain why equity is relatively expensive. This can be because of tax rules, agency costs of equity, and in the case of banks, a comparative advantage in the collection of deposit funds (Taggart and Greenbaum 1978). For other motivations of expensive bank costs of capital see Boot (2001). 


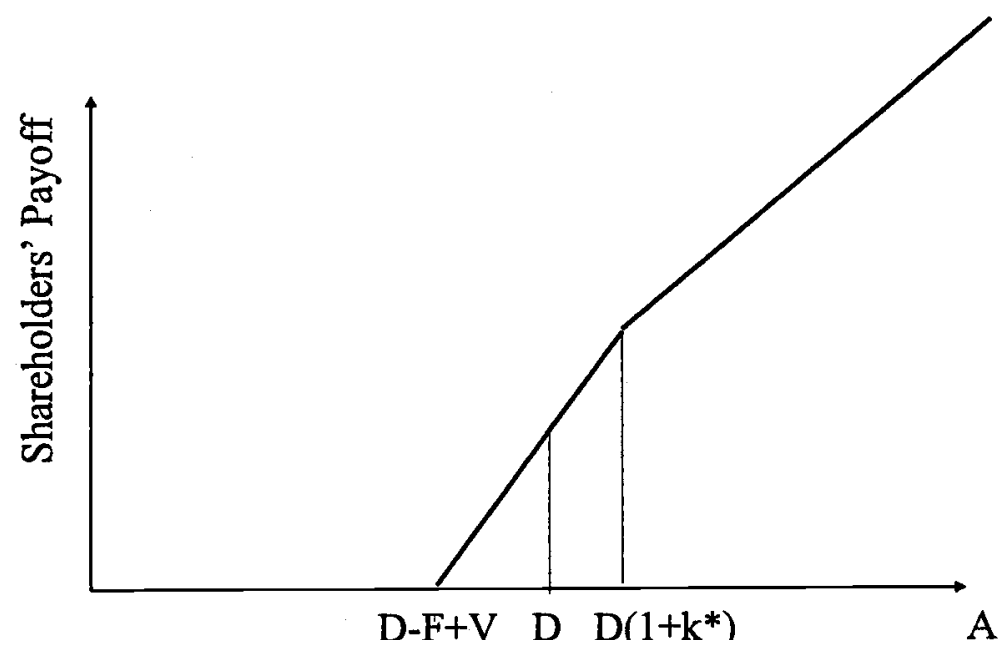

Fig. 8.3 Shareholders' payoff with proportional costs of recapitalization

Note: This figure shows the shareholders' payoff at the next audit time under the option to recapitalize closure rule and proportional costs of recapitalization.

Note that in our analysis the impact of the threshold $\hat{k}$ on the shareholders' payoff comes entirely from the cost imposed on the bank rather than the specifics of the action taken by the regulator (inspections, detailed auditing, etc.).

The shape of this objective function is almost identical to the one presented in Pelizzon and Schaefer (2003) and provides the bank with an incentive to manage its portfolio dynamically. The optimal strategy is characterized by a U-shaped relation between the amount invested in the risky asset and the value of bank assets. This relation has a strong discontinuity. When the bank is solvent it follows a portfolio insurance strategy, which means that the amount invested in the risky asset falls toward zero as the bank's net worth falls to zero. However, when the bank becomes insolvent by even a small amount the amount invested in the risky asset jumps to the maximum possible.

As shown in Pelizzon and Schaefer (2003), this strategy has a strong effect on the distribution of the bank's asset value at an audit time. Moreover, as shown in Pelizzon and Schaefer (2003), under risk management the one-to-one relation between $\pi$ and PVDIL is no longer guaranteed. Indeed, with portfolio revision the asset risk is, in some states, lower than the maximum, and so the average risk is also lower. We might expect, therefore, that both $\pi$ and PVDIL would be lower in the latter case. In fact, while the probability of default is indeed lower, the PVDIL is higher. This occurs because the shape of the distribution in these two cases is different. The rents 


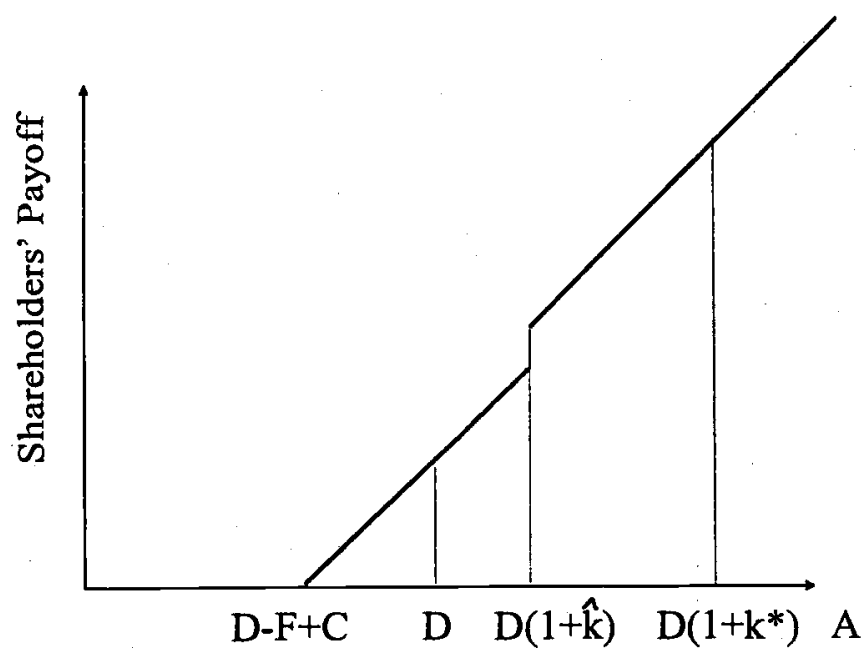

Fig. 8.4 Shareholders' payoff with fix costs of recapitalization

Note: This figure shows the shareholders' payoff at the next audit time under the option to recapitalize closure rule and Pillar 2/PCA fixed costs of recapitalization.

earned by the bank are generated by exploiting the deposit insurance and so, to exploit this source of rents to the maximum, the bank uses risk management to increase the expected loss in those cases where the bank does default, while simultaneously increasing the probability of survival and therefore the length of time the shareholders expect to receive dividends before closure.

A consequence of our analysis is that the value of deposit insurance is different when banks have the ability to engage in risk management. Ignoring this feature is likely to lead to an understatement of the cost of deposit insurance and unreliable conclusions about the consequences of bank capital regulation. These two points are central to the analysis performed in the remainder of this paper.

\subsection{Risk-Based Capital Requirements (Pillar 1)}

Under the 1988 Accord a bank's required capital was a linear function of the amount invested in risky assets. More recent rules rely on the VaR (value-at-risk) framework. In our model there is only one risky asset and therefore, under both the 1988 Accord and the Basel II (i.e., the VaR rule), required capital depends only on $w_{j}$, the fraction of assets invested in the risky asset.

We assume a risk-based capital rule in which the required level of capital is proportional to the amount invested in the risky asset: 


$$
k_{R}=\lambda w_{j} \frac{A_{j}}{D_{j}},
$$

where $k_{R}$ is the required amount of capital expressed as a percentage of deposits and $\lambda$ is the required capital per unit of investment in the risky asset. In the case with constant portfolio positions and normally distributed asset values, for example, $\lambda$ is the product of (1) the number of standard deviations defining the confidence level, (2) the volatility of the rate of return on risky assets, and (3) a scaling factor.

Under this rule, which we apply in the paper, the bank's investment in the risky asset at each portfolio revision date, $w_{j}$, is constrained according to

$$
w_{j} \leq k_{j} \frac{D_{j}}{A_{j}} \frac{1}{\lambda} \equiv \bar{w}\left(k_{j}, \frac{D_{j}}{A_{j}}, \lambda\right),
$$

where $\bar{w}$ represents the maximum permissible investment in the risky asset for a given ratio of deposits to assets and to a percentage of capital $k_{j}$, defined as

$$
k_{j}=\frac{A_{j}-D(1+r)^{1 / n}}{D} .
$$

One of the main objectives of our paper is to analyze the effects of capital regulation on bank risk taking. However, our analysis to this point assumes an environment that is entirely unregulated except for the periodic audits when, if the percentage of capital is lower than $\bar{k}$, the bank must either recapitalize or is closed. Between audits, however, we have assumed that the bank has complete freedom to choose the risk of its portfolio, even if insolvent.

In practice, banks are required to observe capital requirements continuously through time and face censure or worse, if they are discovered, even ex post, to have violated the rules. However, if (1) asset prices are continuous, (2) capital rules are applied continuously through time, and (3) capital rules force banks to eliminate risk from their portfolio when their capital falls below a given (nonnegative) level, a bank's probability of default becomes zero. ${ }^{24}$

With continuous portfolio revision the only way to avoid this unrealistic conclusion is to assume - perhaps not unrealistically — that banks are able to continue to operate, and to invest in risky assets, even when in violation of either, or both, the leverage constraint $(\bar{k})$ and the risk-based capital requirements (RBCR). Without some assumption of this kind the analysis of the effect of capital requirements in a dynamic context is without content. However, in order to say something about the effects of capital require-

24. As mentioned earlier, in this setting, the relevant assumption is the absence of jumps in the value of the entire portfolio, a much less stringent constraint than the absence of jumps for any single claim in the portfolio. 
ments in this case, we must also say something about the extent to which banks are able to deviate from regulatory constraints on leverage and exposure to risky assets. In other words, we have to make assumptions about the extent to which banks are able to cheat.

We consider two different levels of cheating:

1. Extensive Cheating (Ext-Cheat). Here, capital requirements are binding only when there is an audit; at all other times the bank faces no constraints on its portfolio. Moreover, irrespective of its portfolio composition prior to audit, any solvent bank may reorganize its portfolio to meet capital requirements but is then constrained to hold this portfolio up to the next portfolio revision date. In all other periods the portfolio is unconstrained, so the bank satisfies the RBCR audit simply by window dressing its portfolio for the audit date. In this highly ineffective capital-requirements regime, a regulator is able to monitor and control the activities of banks only at the time of an audit.

$$
0<w_{t} \leq k \frac{D}{A} \frac{1}{\lambda} \text { and } 0<w_{t+j \Delta t} \leq 1
$$

2. Limited Cheating (Lim-Cheat). Between two audit dates, the maximum exposure of the bank to the risky asset is the greater of (1) the level determined by its capital at the earlier audit date and (2) the exposure based on its actual capital at the time. Here, the capital requirements regime is much more effective than under the Ext-Cheat rule. Its main deficiency is that banks are able to conceal any decrease in capital from the level observed by the regulator at the previous audit date and are therefore able to invest in the risky asset up to an amount determined either by this amount or their actual capital, whichever is higher.

$$
w_{j} \leq \max \left(k_{j} \frac{D_{j}}{A_{j}} \frac{1}{\lambda} ; k \frac{D}{A} \frac{1}{\lambda}\right) \equiv \bar{w}_{m}
$$

Two points are worth noting here. First, these rules are different only when banks are able to engage in risk management, since otherwise banks choose their portfolios only on the audit date, when, under both regimes, they comply with capital requirements. Second, since in our model a bank is always able to liquidate its holding of risky assets and invest the proceeds in the riskless asset (at which point the risk-based required capital is zero), a bank will never be closed as a result of a violation of RBCR.

\subsubsection{Effect of RBCR on Welfare Function Variables}

We now ask how changes in risk-based capital requirements affect risk taking when banks are able to engage in risk management and when capital requirements are imperfectly enforced. 
In our model at each audit date the bank chooses its level of capital, taking into account the constraints that RBCR place on its decisions. The endogeneity of the bank's capital decision, together with the opportunity for insolvent banks to recapitalize, ${ }^{25}$ are critical determinants of behavior and differentiate our approach from much of the previous literature on RBCR (see Rochet 1992, Marshal and Venkatarman 1999, and Dangl and Lehar 2004).

The four panels of figure 8.5 show the effect of changing $\lambda$, the required capital per unit of investment in the risky asset, on the four welfare function variables: the bank's choice of capital, $k^{*}$, the PVDIL, the probability of default, $\pi$, and the average investment in the risky asset, $\overline{A w}$.

In our model and under both compliance regimes, a bank must be compliant with RBCR at the time of an audit. It is important to stress that the capital decision of the bank at this time is made jointly with its dynamic portfolio policy. Thus the capital decision will take into account the opportunity that the bank will have to invest in the risky asset both (1) at the audit date and (2) between audit dates, where the latter depends on the compliance regime.

Panel A shows the level of capital, $k^{*}$, under Lim-Cheat (dotted line) and Ext-Cheat (solid line). With limited cheating, the banks' choice of capital, $k^{*}$, increases monotonically with the value of $\lambda$. In this case, the initial capital decision establishes a lower bound on the maximum exposure to the risky asset up to the next audit date. For the parameters used in our calculations (see fig. 8.5), it is optimal for the bank to hold an amount of capital, approximately ${ }^{26}$ equal to $\lambda$, that allows it to hold the maximum amount of the risky asset. This result is robust for quite a wide range of parameter values. The only parameter that has a significant effect on the result is the proportional cost of recapitalization, $v$, and when this is high it leads the shareholders to decide initially not to open the bank rather than to hold a lower level of capital.

With extensive cheating, the capital decision is different. When $\lambda$ is below a value of approximately 4 percent, that is, when RBCR are relatively unburdensome, it is again optimal for the bank to comply.

This occurs because our example considers only a limited number of

25. Surprisedly, little research on banking either the level of capital or the franchise value as endogenous, and little research takes into account either the dynamic risk management or the options to recapitalize or close. An analysis of endogenous capital closely related to our own is Froot and Stein (1998). They assume convex costs of capital issue and examine the implications for bank risk management, capital structure, and capital budgeting. But they do not allow for bank regulation or deposit insurance and, since theirs is a static model, they are unable to explore the potential implications of an endogenous franchise value. Another is Milne and Whalley (2001), but they do not consider risk-based capital requirements.

26. The relationship between $\lambda$ and $k^{*}$ is not one-to-one, because the former is the required capital per unit invested in the risky asset and the latter is the amount of capital expressed as a fraction of deposits. If 100 percent of the assets is invested in risky assets, the relation between the two is: $k=\lambda /(1-\lambda)$. 
A

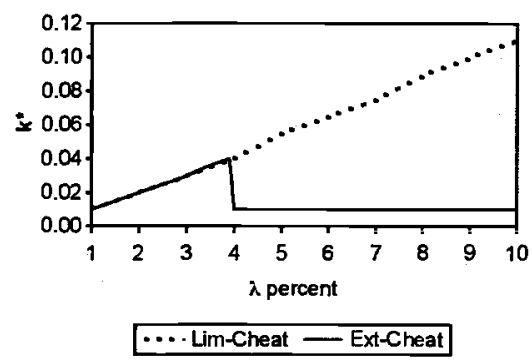

B

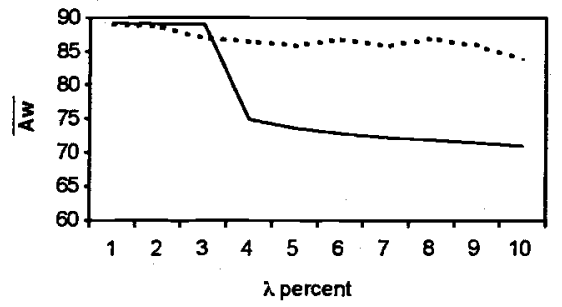

-.. - Lim-Cheat - Ext-Cheat
C

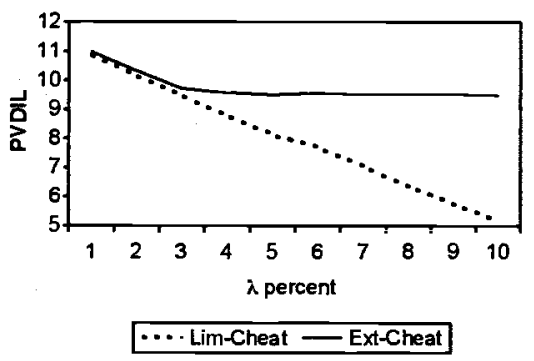

D

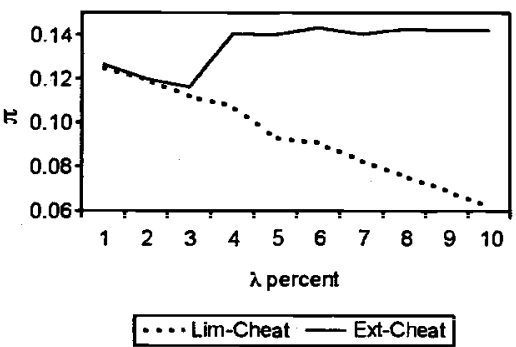

Fig. 8.5 Pillar 1-risk-based capital requirements

Notes: The figure plots the effect of changing the required capital per unit of investment in the risky asset $\lambda$ on the four welfare function variables: capital utilization $k^{*}$, Present Value of Deposit Insurance Liabilities (PVDIL), probability of default $\pi$, and the average investment in risky asset $\overline{A w}$. The parameters used are: $D=100, \hat{k}=1$ percent, $n=4, r=5$ percent, $\sigma=$ 10 percent, $v=5$ percent.

portfolio revision opportunities between audit dates and, in order to invest as much as possible in the risky asset on the audit date (when the bank must comply), the bank chooses a high level of capital. Clearly, if the frequency of portfolio revision were higher (or if recapitalization costs were high), the bank would reduce its level of initial capital.

When $\lambda$ is above 4 percent, the bank's optimal strategy changes and it now chooses a low level of capital and a lower investment in the risky asset on the audit date. At first sight the result that an increase in capital requirements results in both lower levels of capital and less investment in the risky asset may be surprising. We might expect that increasing capital requirements would lead either to higher levels of capital and a maintained level of investment in the risky asset or a maintained level of capital and a lower investment in the risky asset.

This counterintuitive result comes about for the following reason. The amount of capital, $k$, affects the franchise value through the value of the deposit insurance put, the probability of default, and the expected cost of re- 
capitalization. Increasing $k$ allows the bank to increase its holding of the risky asset but also increases the "strike" of the deposit insurance put and, for this reason, an increase in $k$ may either increase or decrease the value of the deposit insurance put, the probability of default, and the expected cost of recapitalization. Therefore, the effect of increasing $k$ on the franchise value may be either positive or negative.

In our example, increasing $k$ leads to increases in the franchise value for values of $\lambda$ below around 4 percent but decreases for values above this level. The threshold level where the bank's policy changes-around 4 percent in this case-is strongly related to the volatility of the risky asset, the frequency of portfolio revision, and the cost of recapitalization.

The effect of changing the capital requirements parameter $\lambda$, on the other three welfare variables can be easily understood in terms of its effect on $k^{*}$.

With Lim-cheat, because (as the regulator would hope), higher RBCR induce the bank to increase capital, the average investment in the risky asset $(\overline{A w})$ remains almost unchanged, the PVDIL and the probability of default decreases monotonically with $\lambda$ (as shown in panels B, C, and D). In this case, we also find that the average investment in the risky asset is little affected by changes in $\lambda$.

With Ext-cheat, the results follow those for $k^{*}$ and fall into two regimes. For low values of $\lambda$ they mirror those for the Lim-cheat case since, in this case, the bank chooses to comply. For higher values of $\lambda$, however, the bank chooses a low level of capital. In this case, the average investment in the risky asset first decreases and then remains unaffected by $\lambda$. Because both PVDIL and the probability of default are insensitive to increases in $\lambda$, RBCR in this case remain ineffective.

Our results emphasize that allowing for the behavioral response on the part of banks in terms of capital and portfolio management is critical to a proper evaluation of the effects of changes in regulation $(\lambda)$. In the QIS carried out by the Basel Committee, the behavioral response was ignored. Our results also show that the behavioral response itself depends on the way the formal rules actually work in practice; that is, the scope they give for banks to cheat.

\subsection{Pillar 1 and Pillar 2 (PCA)}

The results on RBCR in the previous section are presented to provide a benchmark against which to assess the role of Pillar 2/PCA when applied in conjunction with Pillar 1. We investigate this issue for the two cheating regimes described and analyzed earlier.

Recall that, in our framework, Pillar 2/PCA acts as a minimum capital requirement $(\hat{k})$ at the time of an audit, where $\hat{k}>\bar{k}$ - that is, Pillar 2/PCA maximum leverage is a more binding constraint on capital than the simple 
solvency constraint $\bar{k}$. Because it is independent of the composition of the bank's portfolio it therefore acts simply as a constraint on leverage. If a bank violates the Pillar 2/PCA constraint ${ }^{27}$ at audit and chooses to recapitalize, it incurs a fixed cost, $C$, in addition to the variable cost, $v$, described earlier. In our calculations, $\hat{k}$, the maximum capital level, is set at 4 percent.

Figure 8.6 shows the effect on the four output variables from changing the required capital per unit of risky asset, $\lambda$, when Pillar 2/PCA is applied in conjunction with RBCR.

When the level of compliance with RBCR is good (Lim-cheat) - see panels A-D_Pillar 2/PCA has relatively little effect. For values of $\lambda$ above the threshold level $\hat{k}$ the value of $k^{*}$ is driven by RBCR and is effectively unchanged from the result with Pillar 1 alone. The same applies to PVDIL and the average investment in the risky asset. The frequency of default, however, increases, because the fixed cost of recapitalization means that banks will more often choose to close rather than recapitalize. Therefore, when the level of compliance with RBCR is good, Pillar 2/PCA may actually reduce welfare when it increases both banks' costs (recapitalization) and the probability of default.

For values of $\lambda$ below the threshold level $\hat{k}$ the latter becomes the effective minimum value of $k^{*}$. This is because when $\lambda$ is below $\hat{k}$, and even if the bank were to invest entirely in the risky asset, its required capital under $\mathrm{RBCR}$ would be lower than $\hat{k}$. This is reflected in the behavior of $k^{*}$ (panel A), PVDIL (panel B) and $\pi$ (panel C) of figure 8.6.

However, Pillar 2/PCA plays a potentially important role when compliance with RBCR is poor (Ext-cheat). However, as we show, in this case it acts more as a substitute for, rather than a complement to RBCR.

The solid line in panel $\mathrm{E}$ of figure 8.6 shows the value of $k^{*}$ under RBCR from the earlier analysis. The minimum value of capital under Pillar 2/PCA is $\hat{k}$ and the dotted line in panel $\mathrm{E}$ shows that, in our example, this is also the value of $k^{*}$ for all values of $\lambda .{ }^{28}$

Panel (E) shows that Pillar 2/PCA is successful in increasing the level of

27. The prompt corrective action scheme has been in effect in the United States since the passage in 1991 of the Federal Deposit Insurance Improvement Act. The scheme defines a series of trigger points based on a bank's capitalization and a set of mandatory actions for supervisors to implement at each point. The series of actions that FDIC must implement is detailed in the Risk Management Manual of Examination Policies. If a trigger point is violated the first action given in the manual is to require the bank to propose a capital restoration plan. Our closure rule is designed to conform to the spirit of this requirement.

28 . Two points related to $\hat{k}$ in panel (E) of figure 8.6 should be noted. First, in our example, the threshold level of around 4 percent for $\lambda$ that induced a shift in portfolio composition under RBCR happens in this case to be close to the value we have chosen for $\hat{k}$. This means that in panel $\mathrm{E}$ of figure 8.6 the two lines coincide for a value of $\lambda$ close to 4 percent. Second, for values of $\hat{k}$ that are sufficiently low so that it is not a binding constraint for all values of $\lambda$, the value of $k^{*}$ may differ from the value obtained with Pillar 1 alone. The reason is that, although for some value of $\lambda, \hat{k}$ may not be a currently binding constraint, the fact that it may be a binding constraint in some future state of the world may induce a different capital decision now. 
A Limlted Cheating
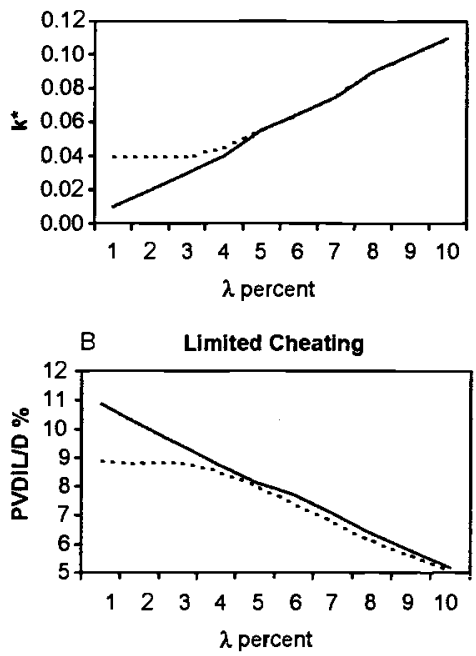

C Limited Cheating
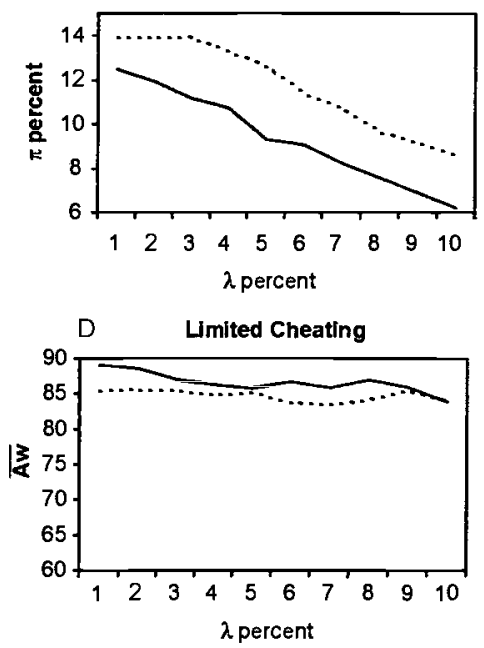

E Extreme Cheating
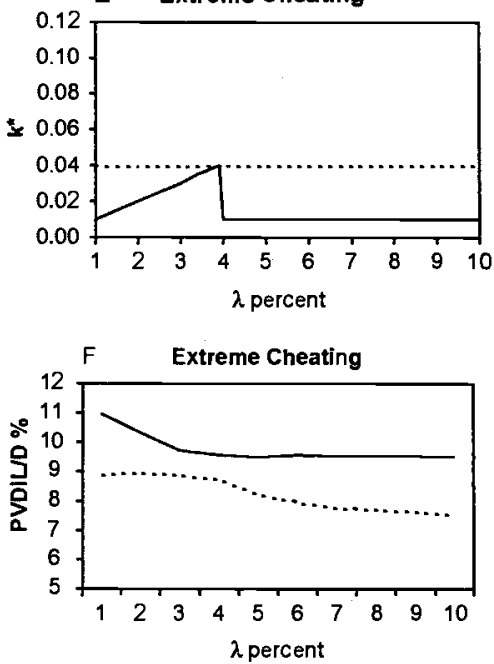

G Extreme Cheating

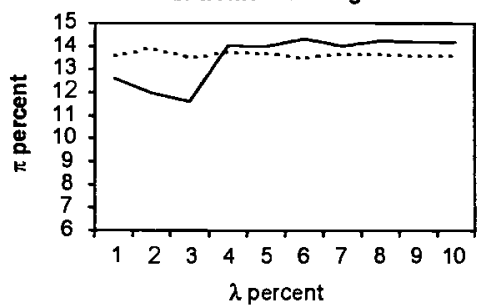

$\mathrm{H} \quad$ Extreme Cheating

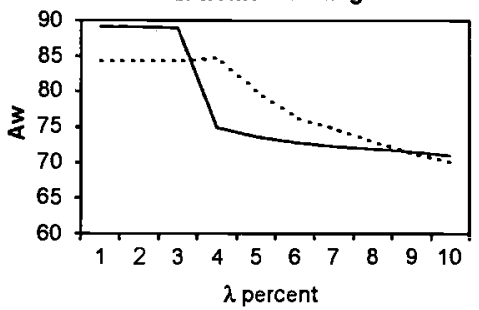

\section{Pillar 1
..... Pillar 182}

\section{Fig. 8.6 Pillar 2/PCA}

Notes: Under Pillar 2/PCA, the figure plots the effect of changing the required capital per unit of investment in the risky asset $\lambda$ on the four output variables: capital utilization $k^{*}$, Present Value of Deposit Insurance Liabilities (PVDIL), probability of default $\pi$, and the average investment in risky asset $\overline{A w}$. The parameters used are: $D=100, \hat{k}=4$ percent, $n=4, r=5$ percent, $\sigma=10$ percent, $v=5$ percent, $C=1$. 
capital that banks hold: in our example, $k^{*}$ is higher for all value of $\lambda$ except 4 percent, where it is the same. However, as panel $\mathrm{E}$ also shows, with poor compliance Pillar 2/PCA does not succeed in reestablishing the link between actual bank capital and RBCR. In other words, it does not correct the ineffectiveness of RBCR that a poor compliance regime produces. Panel E shows that the amount of capital that the bank holds is the same when $\lambda=10$ percent as it is when $\lambda=1$ percent, even though the average risky asset holding in the two cases differs by only about 20 percent. Thus Pillar 2/PCA does not complement RBCR in the sense of increasing the sensitivity of bank capital to $\lambda$.

Panel F of figure 8.6 shows that Pillar 2/PCA does indeed reduce the PVDIL but, as with the level of capital, does so in a way that is almost independent of $\lambda$. Comparing panels $F$ and $G$ shows that this reduction in PVDIL is not brought about by a reduction in the frequency of default $(\pi)$, but as a result of the higher level of capital that banks hold. This reduces the average liability of the deposit insurer compared with the case without Pillar 2. As just mentioned, panel $\mathrm{G}$ shows that there is little effect on the probability of default (except for low values of $\lambda$ ) even though capital levels are higher; this is a result of the fixed cost of recapitalization that leads banks to default more often. For low values of $\lambda$, particularly for values just lower than the threshold value of 4 percent, banks hold more capital than without Pillar 2/PCA and, again as a result of the fixed cost of recapitalization, now default more often.

Finally, panel $\mathrm{H}$ shows that because it forces banks to hold more capital, for $\lambda$ greater than around 4 percent. Pillar 2/PCA allows them to increase the amount they hold in the risky asset. For low values of $\lambda$ the risky-asset holding is actually lower, because the higher threshold level for recapitalization under Pillar 2/PCA means that when asset prices fall the bank reduces its holding in the risky asset (i.e., initiates a portfolio insurance policy) sooner.

\subsection{Conclusion}

This paper investigates the interaction between Pillar 1 (risk-based capital requirements) and Pillar 2/PCA and, in particular, the role of closure rules with costly recapitalization and where banks are able to manage their portfolios dynamically.

In our analysis we make the perhaps extreme assumption that the only source of rents in the banking system is deposit insurance. In a static setting, we know from Merton's (1977) model that banks will choose the portfolio with the maximum risk. However, in a multiperiod setting, taking into account the possibility of costly recapitalization, banks have an incentive to manage their portfolios dynamically. As a consequence, the cost of deposit insurance is affected by the cost of recapitalization and its effect on 
banks' incentive to engage in risk management. In particular, the presence of costs of recapitalization reduce the cost of deposit insurance but increase the probability of default.

A feature of our approach is to consider the costs as well as the benefits of capital regulation and to do so in a way that accommodates the behavioral response of banks in terms of their portfolio strategy and capital structure decisions and, further, the extent to which capital rules are effective - that is, the extent to which banks can cheat.

We measure the effects of capital regulation, for both Pillars 1 and 2, in terms of four output variables that we use as proxies for the costs and benefits - both private and social — of capital regulation.

Without cheating, the problem of bank capital adequacy is relatively minor and is related largely to discontinuity in asset prices, which would lead to difficulties in implementing a stopping policy. However, the regulator faces a much more difficult problem when banks are able to deviate significantly from capital adequacy. Thus, the extent of banks' ability to cheat is fundamental to the analysis of capital requirements. For this reason in our analysis we consider two cases, one with extensive cheating and the other with only limited cheating.

Our results fall into two parts. First, in order to establish a benchmark for assessing the effect of Pillar 2/PCA, we analyze the effect of RBCR in our model with imperfect compliance but without Pillar 2/PCA intervention. In the second part, we introduce Pillar 2/PCA.

Without Pillar 2/PCA, we find that even when banks' compliance is relatively good (limited cheating) RBCR may nonetheless be effective in the sense that, for higher levels of RBCR, banks do indeed hold higher amounts of capital. As result, (1) the PVDIL is lower and (2) the probability of default is also lower. Moreover, we also find that in this case, an increase in RBCR does not reduce the volume of risky assets that a bank is willing to hold (and therefore there does not appear to be a significant negative externality from reduced bank activity).

However, when compliance is poor (extensive cheating), RBCR are ineffective in the sense that for higher levels of RBCR banks do not increase their volume of capital. Consequently, increasing RBCR decreases neither (1) the PVDIL nor (2) the probability of default. Moreover, we find that, in this case, the volume of risky assets held by banks decreases the RBCR increase because banks choose to increase their leverage rather than hold higher volumes of both capital and risky assets.

The degree of compliance with RBCR is similarly crucial in assessing the role of Pillar 2/PCA. If banks were to comply with RBCR continuously Pillar 2/PCA would be redundant. Only where there is the possibility of at least some noncompliance does this type of intervention have a potential role.

We investigate this issue for the two cheating regimes considered in the paper. With limited cheat Pillar 2/PCA has little effect on the level of capi- 
tal that banks choose, the PVDIL or the average investment in the risky asset. The frequency of default, however, increases. The potential role that PVCA/Pillar 2 may play is as a complement to RBCR, not as a substitute. When the level of compliance with RBCR is good, Pillar 2/PCA may actually reduce welfare because it increases both banks' costs (recapitalization) and the probability of default.

However, Pillar 2/PCA plays a potentially important role with extensive cheating, although the results are complex. Introducing Pillar 2/PCA increases the amount of capital that banks hold but does not result in a more effective RBCR regime in the sense that, even with Pillar 2/PCA, increasing RBCR does not result in higher levels of capital. The same result applies to the probability of default, the PVDIL, and the average investment in the risky asset. Introducing Pillar 2/PCA lowers PVDIL but, as before, increasing RBCR does not further strongly reduce PVDIL. For the probability of default the results are mixed but, once again, introducing Pillar 2/PCA does not make the probability of default sensitive to the level of $\mathrm{RBCR}$. The results on the average investment in the risky asset are similarly mixed, but the striking result is that, for higher levels of RBCR, the bank's investment in the risky asset decreases. In general, when extensive cheating is possible, Pillar 2/PCA does not complement RBCR in the sense of making them more effective; rather, they act as a separate, substitute form of regulatory control.

Because we find that Pillar 2/PCA is most effective in reducing the cost of deposit insurance when compliance is relatively poor, we might infer from the fact that (1) in the United States, the FDIC has chosen to introduce PCA after Basel I and (2) the Basel Committee has included Pillar 2, that all these regulators perceive the degree of compliance-for at least some banks - to be relatively poor.

In making this observation it is important to bear in mind that our analysis suggests that, when the level of compliance is high, there may be few benefits to offset the costs of Pillar 2/PCA (the frictional costs of recapitalization).

Both these points suggest that future work in the area of RBCR should pay more attention to compliance rather than simply the design of the rules.

\section{References}

Allen, F., and D. Gale. 2003. Capital adequacy regulation: In search of a rationale. In Economic for an imperfect world: Essays in honor of Joseph Stiglitz, ed. R. Arnott, B. Greenwald, R. Kanbur, and B. Nalebuff, 83-109. Cambridge, MA: MIT Press.

Bank for International Settlements. Press release. "G10 central bank governors and heads of supervision endorse the publication of the revised capital framework.” June 26, 2004. Available at: http://www.bis.org/press/p040626.htm. 
Basel Committee. 1988. International convergence of capital measurement and capital standards. Basel, Switzerland: Bank for International Settlements.

1999. A new capital adequacy framework. Consultative paper. Basel, Switzerland: Bank for International Settlements.

2001. The new Basel accord: Consultative package. Basel, Switzerland: Bank for International Settlements.

2003. The new Basel capital accord: Consultative package. Basel, Switzerland: Bank for International Settlements.

2005. Basel II: International convergence of capital measurement and capital standards: A revised framework. Basel, Switzerland: Bank for International Settlements.

Benston, G. L., \& G. G. Kaufman. 1996. The approximate role of bank regulation. Economic Journal 106:688-97.

Berlin, M., A. Saunders, and G. Udell. 1991. Deposit insurance reform: What are the issues and what needs to be fixed? Journal of Banking and Finance 15:735-52.

Boot, A. 2001. Regulation and banks' incentives to control risk. Sveriges Riksbank Economic Review 2:14-24.

Boot, A., and A. Thakor. 1991. Off-balance sheet liabilities, deposit insurance and capital regulation. Journal of Banking and Finance 15:825-46.

Buser, S. A., A. H. Chen, and E. J. Kane. 1981. Federal deposit insurance, regulatory policy, and optimal bank capital. Journal of Finance 35:51-60.

Campbell, T. S., Y. S. Chan, and A. M. Marino. 1992. An incentive-based theory of bank regulation. Journal of Financial Intermediation 2:255-76.

Chan, Y. S., S. I. Greenbaum, and A. V. Thakor. 1992. Is fairly priced deposit insurance possible? Journal of Finance 47:227-45.

Dangl, T., and A. Lehar. 2004. Value-at-risk vs. building block regulation in banking. Journal of Financial Intermediation 13:96-131.

Descamps, J., J. Rochet, and B. Roger. 2003. The 3 Pillars of Basel II: Optimizing the mix. Journal of Financial Intermediation 13:132-44.

Dewatripont, M., and J. Tirole. 1994. The prudential regulation of banks. Cambridge, MA: MIT Press.

Diamond, D. W., and P. H. Dybvig. 1986. Banking theory, deposit insurance, and bank regulation. Journal of Business 59:53-68.

Duffie, D., and K. J. Singleton. 1999. Modelling term structures of defaultable bonds. Review of Financial Studies (12) 4: 687-720.

Fries, S., P. M. Barral, and W. Perraudin. 1997. Optimal bank reorganization and the fair pricing of deposit guarantees. Journal of Banking and Finance 21:441-68.

Froot, K., and J. Stein. 1998. Risk management, capital budgeting and capital structure policy for financial institutions: An integrated approach. Journal of Financial Economics 47:55-82.

Genotte, G., and D. Pyle. 1991. Capital controls and bank risk. Journal of Banking and Finance 15:805-24.

Goodhart, C., P. Hartmann, D. Llewellyn, L. Rojas-Suarez, and S. Weisbrod. 1998. Financial regulation: Why, how, and where now? New York: Routledge.

Gupta, A., and L. Misra. 1999. Failure and failure resolution in the US thrift and banking industries. Financial Management 28 (4): 87-105.

Hauswald, R. B., and L. W. Senbet. 1999. Public and private agency conflict in banking regulation. Kelley School of Business, Indiana University. Mimeograph.

Hellman, T., K. Murdock, and J. Stiglitz. 2000. Liberalization, moral hazard in banking, and prudential regulation: Are capital requirements enough? American Economic Review (March): 147-65.

Jones, D. 2000. Emerging problems with the Basel Capital Accord: Regulatory capital arbitrage and related issues. Journal of Banking and Finance 24:35-58. 
Kane, E. J. 1990. Principal-agent problems in SL salvage. Journal of Finance 45 (3): 755-64.

Keeley, M. 1990. Deposit insurance, risk and market power in banking. The American Economic Review (December): 1183-1200.

Lando, D. 1997. Modelling bonds and derivatives with default risk. In Mathematics of derivatives securities, ed. M. Demptster and S. Pliska, 369-93. Cambridge: Cambridge University Press.

Marcus, A. 1984. Deregulation and bank financial policy. Journal of Banking and Finance 8:557-65.

Marshall, D., and S. Venkataraman. 1999. Bank capital standards for market risk: A welfare analysis. European Finance Review 2:125-57.

Merton, R. 1997. An analytic derivation of the cost of deposit insurance and loan guarantees. Journal of Banking and Finance 1:3-11.

Milne, A., and Whalley, E. 2001. Bank capital and incentives for risk taking. Unpublished manuscript. London: City University Business School.

Pages, H., and J. Santos. 2003. Optimal supervisory policies and depositorpreference laws. BIS Working Paper no. 131. Basel, Switzerland: Bank for International Settlements.

Pelizzon, L. 2001. Franchise value in a model of bank portfolio management. London Business School. www.ssrn.com. Mimeograph.

Pelizzon, L., and S. Schaefer. 2003. Do bank risk management and capital requirements reduce risk in banking? IFA Working Paper no. 381.

Rochet, J. 1992. Capital requirements and the behavior of commercial banks. European Economic Review 36:1137-78.

Saidenberg, M., and T. Schuermann. 2003. The new Basel Capital Accord and questions for research. Wharton FIC 03-14.

Suarez, J. 1994. Closure rules, market power and risk-taking in a dynamic model of bank behavior. LSE Discussion Paper no. 196. London: London School of Economics.

Suarez, J., and R. Repullo. 2004. Loan pricing under Basel capital requirements. Journal of Financial Intermediation 13:496-521.

Taggart, R., and S. Greenbaum. 1978. Bank capital and public regulation. Journal of Money Credit and Banking 10:158-69.

VonThadden, E. 2004. Bank capital adequacy regulation under the new Basel Accord. Journal of Financial Intermediation 13 (2): 90-95.

\section{Comment Marc Saidenberg}

Pelizzon and Schaefer's paper takes another step in their research program, which examines the implications for regulation of bank portfolio choice in a dynamic setting. The current paper examines the effects of capital requirements under various assumptions about regulators' ability to detect and punish undercapitalization. Some of the paper's ideas have been in the academic literature for many years. For example, the idea that capital re-

The views expressed in this article are those of the author and do not necessarily reflect the position of Merrill Lynch \& Co., of the Federal Reserve Bank of New York, or the Federal Reserves System. 
quirements, regulators' bank closure practices, and deposit insurance pricing are intimately related, with any one of them serving as a sufficient restraint on bank risk taking in simple setups, has been around at least since the early 1990s (for example, Acharya and Dreyfus 1989, Davies and McManus 1991, and Levonian 1991 analyzed closure rules). Pelizzaon and Schaeffer's result, that capital requirements might increase bank risktaking as well as reduce it, was a result in Koehn and Santomero (1980) as well. Another example of a precursor is Ritchken, Thomson, DeGennaro, and $\mathrm{Li}$ (1995), which presents a dynamic model in which banks' ability to alter their risk postures between regulatory audits leads to a richer description of risk taking than in one-period models. ${ }^{1}$

Pelizzon and Schaefer's work represents an important contribution because it brings together many ideas about an important subject in a nice modeling framework. In the richest version of their model, banks choose their risk posture not only at the time regulators examine solvency, but also at points in between such audits (so the regulatory closure rule is not perfectly effective at maintaining solvency). Importantly, banks can completely change their risk posture, without transaction costs, from one moment to the next. Banks face two kinds of capital requirements: a simple leverage ratio and a risk-based capital requirement. The risk-based measure is a perfect indicator of risk posture, and the regulator can observe compliance perfectly at the time of an audit. However, the regulator can observe compliance in between audits imperfectly or not at all. Another important innovation of the setup is that a bank in violation of capital requirements has a (costly) right to recapitalize. Deposit insurance is flat rate and serves only to make the depositors insensitive to risk; that is, the implications of risk-sensitive deposit insurance in combination with rich closure rules and capital requirements are not analyzed, which is a reasonable simplification. The model is nice because many things of interest are endogenous: bank risk posture, capital level, dividend payouts, and the bank's decision whether to recapitalize.

Some of the terminology is a bit different than that used in many other papers. "Risk management" means the bank is able to change its risk posture between audits. In other papers and in the practitioner community, the phrase often refers to the systems and activities that help financial institutions (and other firms) measure, optimize, and control their risk posture. Banks have long been able to change their risk postures in between the annual (or less frequent) examinations that are common in the United States, but modern quantitative risk management systems are a relatively recent innovation.

In Pelizzon and Schaefer's model, "Pillar 2" is the existence of a leverage

1. Berger, Herring, and Szegö's (1995) survey on capital, and Berlin, Saunders, and Udell's (1991) survey on deposit insurance include many references to other related papers. 
ratio capital requirement (alongside a risk-based capital requirement), with violations of the leverage requirement leading to seizure by regulators in the event the bank does not recapitalize, or increased regulatory costs if it does recapitalize. In common parlance, "Pillar 2 " is a term introduced by the Basel Committee on Banking Supervision, and refers to a broad array of regulatory responsibilities and actions.

Although the paper's formal definition of Pillar 2 is narrow, the title of the paper is apt, because the paper's most interesting results flow from varying the assumption about the effectiveness of regulatory monitoring of capital adequacy, and Pillar 2 is all about the effectiveness of regulatory monitoring. As the minimum required capital ratio varies, so do average levels of bank capital, the value of the deposit insurance put option, bank failure rates, and loan volume, but the behavior of such variables of interest is much different when regulatory monitoring is effective than when it is not. Behavior is also different with a leverage ratio capital requirement and a risk-based capital requirement than with a risk-based capital requirement alone.

In drawing conclusions about the efficacy of "Pillar 2," the authors choose to emphasize differences in outcomes between the with-leverageratio and no-leverage-ratio cases, whereas I prefer to focus on differences when regulatory enforcement of capital requirements is less versus more effective. The authors emphasize that "Pillar 2" should be applied with care, because imposition of leverage-ratio capital requirements on top of relatively effectively enforced risk-based capital requirements can be undesirable (bank failure rates increase, and risk taking that perhaps is socially desirable by banks decreases). I prefer to emphasize their finding that good enforcement of capital requirements is better than weak enforcement. Pretty much regardless of whether a leverage-ratio capital requirement is imposed or not, variables of interest behave sensibly (and, in my opinion, desirably) as the risk-based capital requirement is varied when enforcement is good. When enforcement is weak, varying capital requirements often has little effect on outcomes and sometimes has perverse effects. That is, Pelizzon and Schaefer's results imply that Pillar 2 in the Basel Committee's meaning of the term is a good thing. ${ }^{2}$

The subtitle of the Pillar 2 section of the new Basel Accord is "supervisory review process." I can offer a practicing supervisor's perspective of how supervisory review is related to formal capital regulation at very large

2. I prefer to emphasize the enforcement results in part because, in Pelizzon and Schaefer's setup, a bank can costlessly remedy violations of risk-based capital requirements, whereas leverage-ratio violations must be fixed by costly recapitalizations. I suspect the difference in costs is at least in part responsible for the apparently undesirable effects of leverage-ratio requirements on bank failure rates and investment policies. Moreover, leverage ratios and associated PCA mechanisms are present only in a subset of nations, most notably the United States, whereas some form if Pillar 2 (whether weak or strong) is widespread. 
banks. Although supervisory reviews are concerned with many things other than capital adequacy, I will focus only on capital. And I emphasize again that these are my views, not those of the Federal Reserve, and that I focus on large banks.

A paraphrasing of the four principles that appear in the Accord's Pillar 2 section is helpful.

- Each bank should assess internal capital adequacy in light of its risk profile.

- Supervisors should review internal assessments and take action as appropriate.

- Banks should hold capital above regulatory minimums.

- Supervisors should intervene at an early stage to prevent capital from falling below levels appropriate to the risk characteristics of the bank.

Notice that regulatory minimums are mentioned only once, and then with the implication that de facto minimums flowing from banks' internal assessments should usually be the ones that are binding.

Ideally, the real capital requirements flow from Pillar 2. Pillar 1 requirements are an important part of the setup because they represent a framework for relating risk and capital that can help organize the discussion between the bank and supervisor. ${ }^{3}$ But for large banks, which are complex and often at the forefront of financial innovation, the risk measurement schemes embedded in Pillar 1 regulations will always be an incomplete approximation for any given bank.

How would it work in the ideal case? A large bank would have a series of formal risk exposure and capital allocation models, each dealing with different kinds of risks, and a way of aggregating the risk levels and capital requirements the models estimate. For risks that are not formally modeled, the bank would have ad hoc procedures for judging the exposure and adding appropriate capital to the aggregate. Suppose the whole exercise is done monthly, with reporting to senior management (in reality, for risks that can change rapidly, the exercise is done at much higher frequency). Supervisors would review the reports and make their own assessment of capital adequacy relative to risk. To do so, supervisors must understand the nature of the risks the bank takes and the models the bank uses, and this in turn requires a nearly continuous dialog with relevant bank personnel.

Obviously, in such a setup, supervisors would be aware as quickly as the bank itself of major changes in risk posture and capital adequacy. This puts them in a position to intervene early in the sense of suggesting that risk be

3. And, in the event of a disagreement, formal capital regulations provide a set of legally verifiable standards that make it easier for the supervisor to address challenges to its authority. 
shed or capital be raised. But this is neither the most common nor the most important form of supervisory early intervention, because at a wellfunctioning bank, the management would act anyway upon receiving information that capital adequacy or risk has changed. More important is a kind of intervention in the bank's internal procedures. Most of all, supervisors want to be comfortable that the bank understands the risks it is taking and that it has reasonably robust procedures for maintaining capital adequacy. Supervisors are usually reluctant to dictate details of formal models or of procedures. But supervisors are in a good position to notice that a bank may be entirely ignoring a material class of risk, or that its models or procedures are seriously flawed, because supervisors are able to observe the inner workings of many banks.

As large banks have become ever larger and more complex institutions, supervisors have put increasing emphasis on the Pillar 2 processes I have just sketched. It is comforting that Pelizzon and Schaefer's results imply that the improved maintenance of capital adequacy that such processes foster leads to better economic outcomes than situations where supervisory evaluations are infrequent and less effective. Of course, the optimal design of Pillar 2 processes is itself an important research question, and I hope that future work will shed more light on it.

\section{References}

Acharya, Sankarshan, and Jean-Francois Dreyfus. 1989. Optimal bank reorganization policies and the pricing of federal deposit insurance. Journal of Finance 44 (5): 1313-33.

Berger, Allen N., Richard J. Herring, and Giorgio P. Szego. 1995. The role of capital in financial institutions. Journal of Banking and Finance 19:393-430.

Berlin, Mitchell, Anthony Saunders, and Gregory F. Udell. 1991. Deposit insurance reform: What are the issues and what needs to be fixed? Journal of Banking and Finance 15:735-521.

Davies, Sally M., and Douglas A. McManus. 1991. The effects of closure policies on bank risk-taking. Journal of Banking and Finance 15:917-38.

Koehn, M., and Anthony M. Santomero. 1980. Regulation of bank capital and portfolio risk. Journal of Finance 35:1235-50.

Levonian, Mark. 1991. What happens if banks are closed early. Federal Reserve Bank of Chicago. Proceedings of the 27th annual conference on bank structure and competition, 273-95.

Ritchken, Peter, James Thomson, Ramon DeGennaro, and Anlong Li. 1995. Research in Finance 13:219-36. 


\section{Discussion Summary}

Charles Calomiris opened the general discussion with two observations: (1) Pillar 2 cannot be assumed to work, so market discipline is important as well, and (2) during times of stress (meaning reduced solvency), asset substitution by banks is toward risks that often are not socially productive (gambling for redemption), so both regulatory and market monitoring of banks is especially important in crisis situations.

Ross Levine suggested an additional motivation for the tradeoff between failure risk and productive investment that the authors emphasize. Especially outside the industrialized countries, stronger supervisory powers are often used by bank regulators to direct lending to politically favored constituencies, and such loans are often not economically productive.

Patricia Jackson defended the importance of Pillar 2, noting that even the relatively sophisticated formulas of the Basel II Pillar-1 regime will not reflect all the risks faced by banks. With regard to the claim that Pillar 1 was already conservative, it targeted a credit value-at-risk (VaR) percentile, which is the equivalent of a rating riskier than single-A. However, large banks that are systemically important are not likely to be viable if rated riskier than A-minus because many counterparties would refuse to deal with them. Prompt corrective actions triggered by changes in Pillar-1 regulatory capital adequacy almost surely would come too late in such cases. Martin Feldstein added that what amounted to Pillar 2 actions by U.S. bank supervisors seemed to work to prevent a systemic crisis in the late 1980s and early 1990s. Richard Evans noted that many managers of large banks have been concerned that Pillar 2 will be applied inconsistently across nations, but that the recent formation by regulators of a "college of supervisors" offers hope that inconsistencies may be modest. Such cooperation among supervisors may also reduce systemic risk by promoting good cooperation among supervisors internationally in a crisis.

To shed light on whether capital requirements are binding, Martin Feldstein asked for evidence that Basel I increased regulatory capital requirements. Mark Carey recalled that book-capital ratios of U.S. banks reached a trough in the late 1980s and increased substantially after implementation of Basel I, and that recent papers by Mark Flannery and Kasturi Rangan offer evidence that market-price-based measures of bank leverage also imply an increase since the 1980s. Richard Evans observed that large dealer banks strive to choose their leverage based on economic considerations, balancing the need for a buffer stock of capital to support capturing rapidly developing market opportunities with a desire to maximize shareholder value, which sometimes is best done by dividend payouts or share repurchases. However, Basel I requirements have been a constraint at times, and do seem to affect the decision making of some banks. 
Responding to the authors' remarks about the absence of clear discussions in regulatory documents of the market failure that capital requirements are meant to address, Mark Carey observed that such ambiguity arises because regulators have too many hypotheses about the nature of such market failures, not no hypotheses at all, and moreover that intuition suggests that the weight placed on different possible market failures is likely to be different over time, across nations, and in the case of large and small banks. Thus, it is difficult for regulators to produce a concise treatment. But he agreed that research on the nature of such market failures could produce large benefits. 
